\title{
EL GOBIERNO DEL PODER JUCICIAL: SU GARANTÍA DE INDEPENDENCIA ANTE EL TERCER MILENIO
}

M. a VICTORIA GARCÍA-ATANCE GARCÍA DE MORA

Profesora Titular de Derecho Constitucional 


\section{SUMARIO}

introducción. I. Precedentes del autogobierno del Poder Judicial en el DereCho comparado. 1.a) Francia. 1.b) Italia. 2. El órgano de gobierno del Poder Judicial en EsPaña. 2.a) La regulación de la composición del Consejo General del Poder Judicial. 2.a) I. Regulación normativa de la composición del Consejo General del Poder Judicial en la Constitución española. 2.a) II. La regulación de la composición del Consejo General del Poder Judicial en la Ley Orgánica $1 / 1980$ del C.G.P.J. 2.a) III. La regulación de la composición del Consejo General del Poder Judicial en la Ley Orgánica del Poder Judicial 6/1985, de 1 de julio. 2.b) Funciones de gobierno del Consejo General del Poder Judicial. 2.b) I. Las funciones del Consejo General del Poder Judicial reguladas en la Ley Orgánica del Consejo General del Poder Judicial 1/1980, de 10 de enero. 2.b) II. Las funciones del Consejo General del Poder Judicial en la Ley Orgánica del Poder Judicial 6/1985, de 1 de julio. Reforma de la Ley Orgánica 16/1994. 2.c) El estatuto jurídico de los miembros del Consejo General del Poder Judicial. 3. El estatuto jurídico de los miembros del Consejo GeNeral del Poder Judicial 


\section{EL GOBIERNO DEL PODER JUDICIAL: SU GARANTÍA DE INDEPENDENCIA ANTE EL TERCER MILENIO}

POR

M. ${ }^{a}$ VICTORIA GARCIA-ATANCE GARCÍA DE MORA

Profesor Titular de Derecho Constitucional

\section{INTRODUCCIÓN}

Con carácter general, cabe afirmar que el concepto de independencia que debe presidir el poder judicial alcanza su base garantística a través de la fomulación constitucional que se verifica mediante tres vías': a través de la reserva de Ley Orgánica para su configuración; la inamovilidad de los jueces, y el régimen de incompatibilidades que deben presidir el ejercicio de su cargo.

Pero además el sentido de independencia del poder judicial cabe predicarse en mayor o menor medida del hecho de que tanto el Gobierno, como la administración del aparato jurisdiccional recaigan o no sobre órganos ajenos al mismo, por lo que cabe afirmar el gobierno de la magistratura a través de su propio Consejo como garantía prioritaria a las formuladas antes, y que tiene expresa cobertura constitucional (art. 122.2), frente a la errática idea de "autogobierno» ${ }^{2}$ del poder judicial; que

1 Fernández-Miranda Campoamor, C.: «El Consejo General del Poder Judicial: de la Ley Orgánica de 1980 a la Ley Orgánica de 1985", en Revista de Derecho Politico, n. ${ }^{\circ} 38$, UNED, Madrid, 1993, pág. 40.

2 En oposición al término "autogobierno" como ha diferenciado un significativo sector de la doctrina: Pérez Rovo, J.: Curso de Derecho Constitucional, MARCIAL 
no cabe deducirse de la Constitución, ni de la configuración y competencias del propio Consejo, nos guste o no, ni de la jurisprudencia constitucional, tal como se dedujo de la Sentencia T.C. 108/86 de 29 de julio. Nos hallamos, pues, en presencia de un órgano cuyo gobierno, precisamente por la indole de las funciones que realiza -de naturaleza puramente administrativa- se justifica por su finalidad instrumental, como señala Xiol Ríos ${ }^{3}$, a través de la adecuada organización del poder judicial, orientada a defender la independencia de los jueces y magistrados. $Y$ ello se consigue -como ha señalado el Tribunal Constitucional ${ }^{4}$ - no siendo el órgano de autogobierno de los jueces; sino por asumir una posición autónoma y no subordinada a los demás poderes públicos.

\section{PRECEDENTES DEL AUTOGOBIERNO DEL PODER JUDICIAL EN EL DERECHO COMPARADO}

En el ámbito del Derecho comparado, y sin ser nuestra pretensión analizar las diversas plasmaciones que se han reflejado en la postguerra, podemos mencionar algunos precedentes de la constitucionalización de esta garantía de independencia del poder judicial.

Efectivamente, las facultades que durante el constitucionalismo liberal el poder ejecutivo proyectó sobre el poder judicial, a pesar de predicarse su independencia ${ }^{5}$, fueron cediendo poco a poco; si bien el ejecutivo no renunció al gobierno del poder judicial (a través del Ministerio de Justicia) hasta el constitucionalismo de la postguerra, y aún así con reservas, como en el caso francés. Dentro de nuestro entorno inmediato, la Constitución francesa de la IV República de 1946; así como posteriormente la de 1958 de la V República; la italiana de 1947 $\checkmark$ el modelo portugués, han influido en mayor o menor medida en nuestro sistema de gobierno del Poder Judicial; y no así Estados Unidos ni el Reino Unido: países en los que se aprecia una fuerte intervención del Ejecutivo en su sistema organizativo judicial.

Pons, Ediciones Jurídicas, S.A., Madrid, 1994, pág. 629; y Torres del Moral, A.: Principios de Derecho Constitucional españoln, 3. ${ }^{2}$ ed., Madrid, 1992, volumen 2, pág. 283.

3 XIoL Ríos, J.A.: El poder judicial y su consejo general, en el estado social y democrático de Derecho. Premio Poder Judicial, C.G.P.J., Madrid, 1990, pág. 26.

4 Sentencia Tribunal Constitucional 108/86, de 29 de julio, BOE 193; Fundamento jurídico, n. ${ }^{\circ} 10$. 283.

5 Torres del Moral, A.: Principios de Derecho Constitucional ..., ob. cit., pág. 
- Por lo que podemos señalar como referentes en la organización y configuración de nuestro Consejo:

- El modelo napoleónico que se caracteriza por un intervencionismo del ejecutivo relevante; proyectando una autonomía judicial respecto al Gobierno, pero sin darle una independencia absoluta.

- El modelo italiano, que refleja una superación del tipo francés $\checkmark$ en el que se refleja una equilibrada conjunción del ámbito democrático representativo y participativo.

- Y, por último, en sentido negativo, algunos de los aspectos de nuestro propio Consejo General del Poder Judicial reflejado en la Ley Orgánica de 1985, como modelo de lo que no debe ser un Consejo de Gobierno del Poder Judicial.

El ejemplo que ha proyectado en nuestro modelo constitucional la formulación del órgano especial de gobierno del poder judicial consolidado en la Constitución Italiana, le ha valido el reconocimiento del sistema "a la italiana", fundamentalmente por haberse fraguado en este modelo, así como por haberse formulado con mayor concreción incluso que en el caso francés ${ }^{6}$.

Veremos a continuación más pormenorizadamente estos modelos del Derecho comparado que más han influido en el diseño del órgano español al que hacemos referencia, conviniendo en todo caso con un sector de la doctrina -Porras Nadales - al afirmar que con carácter general, cabe señalar el período de entreguerras europeo -hipocentro de la crisis del estado liberal-como impulsor natural de un control jurídico del poder judicial -es decir, sujeto exclusivamente a la ley-, en el marco de un estado crecientemente intervencionista.

\section{1.a) Francia}

El Consejo Superior de la Magistratura en la Constitución de 1946. Ocupa un lugar común en la doctrina ${ }^{8}$ el reconocimiento de que

6 Mosouera, L.: «La posición del poder judicial en la Constitución Española de 1978", en La Constitución Española de 1978: Estudio sistemático, Pedrieri y Enterría.

7 Porras Nadales, A.J.: El Consejo General del Poder Judicial, según la Sentencia 108/1986 de 29 de julio sobre la L.O.P.J., pág. 226.

8 Lucas Murillo de la Cueva, P.: «El Gobierno del Poder Judicial: los modelos y el caso español", en Revista de las Cortes Generales, $n .{ }^{\circ} 35,2 .^{\circ}$ cuatrimestre, 1995. Publicaciones del Congreso de los Diputados, Madrid, 1995. 
el precedente de la institución que nos ocupa residió en la Constitución Francesa de la IV República de 26 de diciembre de 1946, cuyo título IX regulaba el Consejo Superior de la Magistratura; al que se le dotaba de determinadas facultades conducentes a garantizar cierta autonomía judicial respecto al Gobierno, pero sin que ello implicara tampoco una independencia absoluta ${ }^{9}$, como se deduce del específico elenco de funciones reconocidas al Conseil y que referimos a continuación:

- Asegurar la disciplina judicial.

- Propuesta al Presidente de la República del nombramiento de todos los magistrados, a excepción del Ministerio público.

- Aconsejar al Jefe del Estado sobre los recursos de gracia.

El Consejo, formado por 14 miembros, era presidido por el Presidente de la República y siendo el propio Ministro de Justicia su Vicepresidente, y está compuesto además por 6 miembros elegidos por la Asamblea fuera de su seno (por mayoría de $2 / 3$ ); 4 jueces representantes de cada categoria judicial (jueces de paz; tribunales de 1. instancia; tribunal de apelación y tribunal de casación) y por 2 miembros elegidos pro el Presidente de la República, de entre el ámbito jurídico, pero sin pertenecer a la Asamblea ni a la Magistratura, según expresa el art. 83 y 84 de la Constitución de 1946.

El Consejo Superior de la Magistratura en la Constitución Francesa de la V República

\section{Composición:}

La Constitución Gaullista de 1958 regula en sus artículos 64 y 65 la institución que analizamos, reduciendo el número de miembros del Consejo Superior de la Magistratura a 11, reflejando en el texto constitucional el sistema de elección únicamente del Presidente y Vicepresidente, y remitiendo a la Ley Orgánica ${ }^{10}$ el sistema de elección aplicable para los otros nueve miembros, y que se concreta en la designación por

9 Garcia-Pelayo, M.: Derecho Constitucional Comparado, Alianza Universal Textos, Madrid, 1984, pág. 515. de 1958.

10 Ley Orgánica recogida en la Ordenanza n. ${ }^{\circ}$ 58-1271 de 22 de diciembre 
el Presidente de la República de 3 Magistrados del Tribunal de Casación, otros 3 Magistrados de Juzgados y Tribunales, de entre una lista configurada por aquel Tribunal; y por último, 1 Consejero del Estado de la terna que haya presentado el Pleno de tal institución (Consejo de Estado), y 2 juristas de prestigio, elegidos libremente por el Presidente.

\section{Competencias:}

Las facultades con que cuenta el Conseil Superieur de la Magistrature se cifran en:

- Dictaminar sobre los indultos.

- Decidir sobre las propuestas por parte del Ministerio de Justicia relativas al nombramiento de otros jueces.

- En materia disciplinaria, adopta una configuración específica recayendo, a este efecto, la Presidencia en el Presidente del Tribunal de Casación.

- Estas competencias no proyectan en todo caso una eficacia decisoria del Consejo -a excepción de la esfera disciplinaria- por lo que se planteó la conveniencia de ciertas modificaciones ${ }^{11}$ conducentes a alcanzar mayores cotas de independencia externa de tal institución y desarrollo legal de la Constitución.

\section{Modificaciones de 1993 y 1994}

Sin embargo, la Ley Constitucional 93-952 de 27 de julio de 1993 produjo el efecto de pérdida por parte del Consejo de determinadas facultades que disfrutaba hasta entonces, como lo era la exigencia de consultar al Consejo ante los supuestos del ejercicio del derecho de gracia.

Y en materia de composición de los miembros del Consejo, lo más significativo se cifra en la modificación numérica -que pasa a ser de 12 miembros-, así como en el régimen de elección de sus miembros, cuya propuesta para el nombramiento de los Magistrados ve desplazado el centro de gravedad al Parlamento, frente a lo que acontecía con anterioridad, en que el Presidente de la República gozaba de amplios poderes discrecionales, y cuya formación es la siguiente:

liard.

11 Como la propuesta por Hubert Dalle, Presidente del Tribunal de Montbe- 
- Presidente de la República.

- Ministro de Justicia

- Vicepresidente del Consejo.

- Un consejero de Estado, elegido por la Asamblea General del Consejo de Estado.

- Tres miembros designados por el Presidente de la República.

- Tres miembros designados por la Asamblea Nacional.

- Tres miembros designados por el Senado.

La importante intervención del Parlamento en la composición del Consejo, introducida por la modificación de 1993, se matizaría aún más con la modificación que introdujo la modificación de 1994 y que vemos a continuación.

\section{La Ley Constitucional 94-100 de 5 de febrero de 1994}

A la mencionada modificación introducida en el 93, la posterior verificada en 1994 aporta la novedad de configurar lo que se reconoce como una plataforma de fiscales que formen parte necesariamente del Consejo, así la composición de la institución deberá contar en todo caso con:

- Un abogado del Tribunal Supremo.

- Un Fiscal General de un Tribunal de Apelación.

- Un Fiscal del Tribunal de la República.

- Dos fiscales.

- Un Magistrado.

Introduce asimismo la Ley de 1994 específicos dispositivos y condiciones en torno al procedimento de elección de tales personalidades, que por su complejidad, no vamos a analizar aquí.

- En lo que concierne a las competencias de que disfruta la institución, debemos señalar una doble vertiente que, en términos genrales, ha supuesto una buena aceptación social de las reformas introducidas por las dos leyes orgánicas que venimos analizando:

- El dictamen del Consejo es vinculante para la propuesta del nombramiento de los Magistrados del Consejo, dejando de ser el Presidente de la República quien nombre a determinados miembros del Consejo, como sucedía con anterioridad, sino que pasa a ser competencia del propio Consejo. 
- El dictamen del Consejo no es vinculante para el nombramiento de la plataforma de los fiscales miembros del Consejo.

- Este último aspecto configura, acaso, el punto negro de la -en términos generales- afortunada reforma de la institución, al no haber faltado alguna crítica en la doctrina ${ }^{12}$ que ve en este régimen de nombramientos, una magnífica oportunidad perdida por el Consejo de reforzar su autonomía frente al Presidente de la República.

\section{1.b) Italia}

II Consiglio Superiore della Magistratura.

A pesar de encontrar un instituto italiano existente en $1907^{13}$, denominado asimismo con este título, si bien con muy disminuidas facultades en lo que consideramos hoy que debe asumir un órgano de esta índole, esta institución italiana tiene su inspiración en el modelo francés del Conseil Superieur de la Magistrature de 1946, que estaba dotado de mayor grado de independencia del ejecutivo, que el diseñado en la Constitución de 1958.

Respondiendo con más semejanza al modelo francés de 1946, el Consejo Superior de la Magistratura en Italia, garantiza en gran medida la independencia del poder judicial en este país. A pesar de que en España, como afirma De Esteban ${ }^{14}$, existen antecedentes de este tipo de órganos, cabe señalarlo sin embargo, como ejemplo próximo y de manera muy singular ${ }^{15}$ en la configuración de nuestra institución, recogida en el artículo 122.2 de la Constitución Española; lo que ha conducido a reconocer esta institución "a la italiana», como señala Mosquera ${ }^{16}$, tanto por haberse consolidado allí, como por haberse

12 Lucas Murillo de la Cueva, P.: “El Gobierno del Poder Judicial: los modelos y el caso español», ob. cit., pág. 188.

13 Bustillo Bolado, r.: "El autogobierno del Poder Judicial en Europa», en Poder Judicial, n. ${ }^{\circ}$ 37, C.G.P.J., Madrid, marzo, 1995.

14 De Esteban, J. y López Guerra, L.: El Régimen Constitucional español, nota n. ${ }^{\circ} 329$, Labor Universitaria, Barcelona, 1980. Hace referencia a un órgano denominado Consejo Judicial, al que alude Almagro Nosete en su «Informe sobre el anteproyecto de Bases para una Ley Orgánica de la Justicia", Revista de Derecho Procesal lberoamericana, marzo, 1969.

15 Alonso de Antonio, J.A. y A.L.: Derecho Constitucional Español, Editorial Universitas, Madrid, 1996.

${ }_{16}$ Mosouera, L.: «La posición del Poder Judicial en la Constitución Española de 1978", en La Constitución Española de 1978: estudio sistemático, 2. ${ }^{2}$ edic., Civitas, Madrid, 1981, García de Enterría, E. y Predieri, A. 
perfeccionado su regulación, como, finalmente, por haberse formulado con mayor coherencia que en el modelo francés, al lograr el Consiglio Superiore della Magistratura mayor garantía de independencia del Poder Judicial respecto al ejecutivo, que el Conseil francés.

\section{Composición:}

Su primera aparición en la organización judicial italiana hay que situarla en la Ley 511/1907 de 14 de julio, cuyo artículo 34 reflejaba la existencia de un órgano consultivo cuyo Presidente lo era asimismo de la Corte di Cassazione de Roma y su Procuratore Generale, así como 6 Consejeros y 3 procuradores sustitutos de Casación designados por la Corte de Casación y nombrados por el Ministerio, y 9 magistrados de grado no inferior al de Primer Presidente de la Corte de apelación, a propuesta del Ministro de Justicia.

Por último, se determina la asignación de 3 consejeros y un sustituto como suplentes.

El sistema electivo que contemplaba originariamente la institución que analizamos, sufriría una modificación con la Ley 1311/1912 de 19 de diciembre, estableciendo el nombramiento de sus miembros por Real Decreto, a propuesta del Ministro de Justicia; la caída del régimen fascista comportaría el restablecimiento del sistema electivo anterior.

Sin embargo, es realmente la Constitución de 1947, artículo 104 y siguientes, la que posibilitó el autogobierno de la Magistratura, determinando su composición del siguiente modo:

- Presidente de la República, como Presidente.

- Presidente de la Corte de Casación.

- El Procurador General de la Corte de Casación.

- Otros componentes de los que 2/3 serían elegidos por la Magistratura entre todas las categorías, y $1 / 3$ por el Parlamento -en sesión conjunta de ambas Cámaras- de entre profesores de universidad y abogados con 15 años de ejercicio.

La Ley 195/1958 de 24 de marzo procedió al desarrollo del texto constitucional, que sería a su vez modificada con posterioridad por la Ley $695 / 1975$ de 22 de diciembre, quedando su régimen de elección como sigue, haciendo gala de un talante democrático en su composición:

- 3 miembros por derecho propio.

- 20 magistrados elegidos por los magistrados ordinarios pertenecientes a las distintas categorías de la carrera.

- 10 Consejeros elegidos por el Parlamento. 


\section{- Competencias:}

Los artículos 104 a 106 de la Constitución italiana de 1947 reflejan la existencia de un órgano -art. $104-$ autónomo $^{17}$ e independiente ${ }^{18}$ de cualquier otro poder al que no cabe atribuírsele la representación del Poder Judicial, ni siquiera ... la representación procesal del mismo ${ }^{19}$.

El artículo 105 de la Constitución italiana asigna específicamente al Consejo las competencias siguientes:

La admisión, la asignación, el traslado, los ascensos, la potestad reglamentaria y las medidas disciplinarias relativas a los magistrados; respecto a esta última, hay que mencionar que sin perjuicio de su intervención con la asistencia de todos los componentes de la Comisión, la iniciativa, propiamente dicha, disciplinaria es competencia exclusiva del Ministro de Justicia, como define el artículo 107 de la Constitución. Estas facultades se verifican a través de determinadas instituciones como son:

- El Comité de Presidencia.

- Las Comisiones.

- La sección disciplinaria.

Esta actividad disciplinaria, como ha afirmado cierto sector de la doctrina italiana ${ }^{20}$, que es ejercida por una específica sección del Consejo Superior como se indicó, asume el carácter de jurisdicción especial, y las decisiones adoptadas por aquélla tienen naturaleza de sentencia, pudiendo ser recurridas en casación, en aplicción del art. 111 , apart. 2 Constitución y art. 17 , apart. $3 .^{\circ}$, de la Ley de 24 de marzo de 1958.

Podemos diferenciar, en términos generales, las atribuciones que corresponden al Consejo ${ }^{21}$ en los grupos siguientes:

17 Porras Nadales, A.: "El Consejo General del Poder Judicial», en Revista Española de Derecho Constitucional, año 7, n. ${ }^{\circ} 19$, enero-abril 1987, pág. 226.

18 Pizzorusso, A.: "The ordinary Judiciary (Magistratura ordinaria) constitutes an autonomous order, independent from any other power of the Staten, en Judicial independence: the contemporary debate, AA.VV., Ed. Shimon Shetreet of Jerusalem and Jules Deschênes, Superieur Court of Quèbec, Boston, Lancaster, 1985, pág. 196.

19 Porras Nadales, J.A.: "Los conflictos entre órganos constitucionales y principio de separación de poderes", en Revista de Estudios Políticos. Centro de Estudios Constitucionales, n. ${ }^{\circ}$ 52, Madrid, 1986, pág. 32.

20 Pizzonusso, A.: Lezioni di Diritto Costituzionale, ed. de II Foro Italiano, Roma, 1981, pág. 415. pág. 514 .

21 Biscaretti di Ruffia, P.: Derecho Constitucional, Tecnos, Madrid, 1973, 
a) De propuesta al Ministro de Justicia: sobre modificaciones de las circunscripciones judiciales y sobre otras materias relativas a la organización y funcionamiento de los servicios de la justicia.

b) Consultivas: relativas a los proyectos de ley que conciernen al ordenamiento judicial y a la administración de justicia.

c) Deliberativas, que son las mencionadas con anterioridad y que conciernen a:

c.1) La promoción a la magistratura, ascensos, traslados y asignación de puestos.

c.2) Nombramiento y revocación de los miembros de las secciones especializadas de la magistratura.

c.3) Las sanciones disciplinarias, como consecuencia derivada de la acción disciplinaria incoada en la correspondiente sección disciplinaria del Consejo.

c.4) La designación para el nombramiento del Magistrado del Tribunal de Casación por méritos notables, de entre profesores y abogados.

Finalmente cabe mencionar que las decisiones del Consejo Superior de la Magistratura se publican por decretos presidenciales refrendados por el Ministro de Justicia, que constituyen simples actos debidos $^{22}$ ejecutores de las deliberaciones del Consejo, y frente a los que siempre cabe la normal impugnación en el sentido del artículo 113 de la Constitución.

- Régimen de incompatibilidades de los miembros del Consejo Superior de la Magistratura:

Aparte de las expresamente recogidas por el artículo 104 de la Constitución italiana de 1947, en relación con la prohibición expresa de ser inmediatamente reelegibles y recaer asimismo sobre ellos la prohibición del ejercicio de su profesión, así como de pertenecer al Parlamento o a un Consejo Regional; la ley ha precisado más pormenorizadamente el elenco de incompatibilidades en que incurren los miembros del órgano de gobierno de la Magistratura:

- No pueden formar parte de la Corte Constitucional.

- No puede asumir el cargo de Ministro ni Subsecretario de Estado.

- No pueden ser titulares de empresas comerciales ni formar parte de Consejos de Administración de Sociedades Comerciales.

22 Pizzorusso, A.: Lezioni di Diritto Costituzionale, ob. cit., pág. 415. 


\section{EL ÓRGANO DE GOBIERNO DEL PODER JUDICIAL EN ESPAÑA}

\section{2.a) La regulación de la composición del Consejo General del Poder Judicial}

2.a) I. Regulación normativa de la composición del Consejo General del Poder Judicial en la Constitución Española

El Consejo General del Poder Judicial que recogía el Anteproyecto de constitución en su artículo 112.3:

«El Consejo General del Poder Judicial estará integrado por el presidente del Tribunal Supremo, que lo presidirá, y por veinte miembros nombrados por el Rey, doce de ellos a propuesta y en representación de las distintas categorías de las carreras judiciales y ocho a propuesta del Congreso de los Diputados entre juristas de reconocida competencia con más de quince años de ejercicio en su profesión".

sufriría modificaciones antes de su redacción definitiva. Atendiendo al texto del anteproyecto, así como a los votos particulares que se presentaron durante su tramitación, se deduce uniformidad en aspectos puntuales como era:

- Una opción híbrida y dispar de Gobierno cristalizada en un órgano autónomo.

- Configuración por un conjunto de expertos jurídicos.

- Composición mixta entre jueces profesionales y otros juristas.

- Por último en el hecho de que la Presidencia del Consejo corresponda a la del Tribunal Supremo, siendo designado a propuesta del propio Consejo.

No es constatable, por el contrario, afinidad en otros aspectos, como se deduce del voto particular del Grupo parlamentario UCD, en lo que concierne a:

- La referencia al Gobierno en la Administración de Justicia; proponiendo UCD que sea referida al Poder Judicial.

- El número de vocales que presenta el Anteproyecto de 20, proponiendo UCD 15.

- La propia designación de los vocales del órgano de Gobierno, que el Anteproyecto refleja, mientras que el voto particular lo relega a la ley. 
- La condición de la categoría judicial como requisito que el anteproyecto incluye, y no asi el voto particular.

En lo referente al criterio adoptado relativo a la intervención de diversos órganos competentes para la elección de los miembros del Consejo, conviene señalar que frente a la opción del texto del Anteproyecto que lo hacía recaer en 12 por los jueces y 8 por el Congreso, un significativo número de enmiendas invocaba distintos criterios al respecto:

- Minoría Catalana (enmienda $n .^{\circ}{ }^{164}$ ) proponía que de los 20 miembros, 12 lo fueran por los jueces y 8 por el Congreso, contando con un quorum de $3 / 5$ ).

- Socialistas de Cataluña (enmienda n. $^{\circ}$ 293) y Socialistas del Congreso (enm. $n .^{\circ} 436$ ) pretendian acusar la intervención del Congreso que designaría 12 vocales y 8 los jueces.

- El Grupo Vasco (enmienda . $^{\circ} 643$ ) optaría por una posición ecléctica entre ambas alternativas anteriores: 10 miembros serían elegidos por el Congreso y 10 por los jueces, pretendiendo garantizar así la ausencia de tensión por el predominio y relevancia de una u otra institución apta a intervenir en la designación de los miembros del órgano de Gobierno.

En el recorrido de su iter legislativo, el informe de la Ponencia reflejaría necesariamente el peso de la representación del Grupo Parlamentario de UCD, de forma que la ponencia elevó la siguiente redacción:

«El Consejo General del Poder Judicial estará integrado por el Presidente del Tribunal Supremo, que lo presidirá, y por quince miembros nombrados por el Rey, por un período de cinco años. Diez entre Jueces y Magistrados, en los términos que establezca la Ley Orgánica y cinco a propuesta del Congreso de los Diputados, elegidos por mayoría de tres quintos de sus miembros, entre juristas de reconocida competencia, con más de quince años de ejercicio de su profesión".

El espíritu de consenso que inspiró en términos generales el proceso constituyente, se hizo sentir de forma concreta en el tema que nos ocupa, durante el debate del Informe en la Comisión de Asuntos Constitucionales y Libertades públicas.

En el seno de la Comisión, unos y otros grupos hicieron concesiones. Una de las cuales, precisamente la que defendía UCD relativa al número de componentes del Consejo, y en virtud de la cual variaría el número de miembros, de 15 a 20 , repercutiría muy significativamente debilitando el componente judicial. 
El dictamen presentado por la Comisión sería ratificado por el Pleno del Congreso con un resultado más que elocuente de la armonía $y$ equilibrio, consenso, en fin, alcanzado en esta etapa, no arrojando ningún voto en contra, y sólo 3 abstenciones:

«El Consejo General del Poder Judicial estará integrado por el Presidente del Tribunal Supremo, que lo presidirá, y por veinte miembros nombrados por el Rey, por un período de cinco años. Doce entre Jueces y Magistrados de todas las categorías judiciales y ocho por el Congreso, en los términos que establezca la Ley Orgánica, elegidos por mayorías de tres quintos de sus miembros, entre abogados y otros juristas de reconocida competencia, con más de quince años de ejercicio en su profesión".

La anterior redacción sufriría al pasar por el Senado una notable modificación relativa al número de miembros propuestos por el Parlamento, y que variaría de los 8 contemplados por el Congreso, a ser únicamente 4 y otros 4 por el Senado, quedando, por lo demás, igual la redacción.

- Caracteres generales de la regulación constitucional del órgano de Gobierno del Poder Judicial:

a) El Consejo no forma parte del poder judicial integrado exclusivamente por jueces y magistrados, ni representa al poder judicial, sino que garantiza la independencia jurídica de éste.

b) Relacionado con el punto anterior, y como consecuencia de ello, hay que mencionar que el Consejo carece de competencias jurisdiccionales, disfrutando sólo de competencias administrativas.

c) La Constitución referencia expresamente determinados ámbitos competenciales al Consejo, para aislar o alejar de ellos al ejecutivo, que tradicionalmente se valió de ellos para influir y condicionar el poder judicial, y aún asi, insuficientemente, quedando una franja competencial común para el Consejo y para el Ministerio de Justicia; lo que se refleja en el Libro Blanco de la Justicia como desideratum.

d) La Constitución define al Consejo como "el órgano de Gobierno del poder judicial", entendiendo por "poder judicial», en sentido estricto, los jueces y magistrados, esto es, los que administran la justicia, tal y como se desprende del art. 117.1, al margen de que en el título VI y bajo la rúbrica de Del Poder Judicial, se recojan otros ámbitos-como el personal al servicio de la justicia, o la policía judicial-que pueden inducir a pensar que son también poder judicial -como tercer poder del Estado que juzga y hace ejecutar lo juzgado- lo cual es ine- 
xacto. Como ha señalado Mosquera ${ }^{23}$, el elemento nuclear y definitorio del poder judicial es predicable exclusivamente de jueces y magistrados, al margen de que bajo el mismo título se hayan incluido otros elementos sea de la organización judicial o de su funcionamiento pero que, aun teniendo relación con dicho poder, no forman parte de aquél de manera sustantiva y principal; siendo precisamente este ámbito, el que suscita aquella ambigüedad competencial mencionada anteriormente, como una franja común para el Consejo de Gobierno y para el Ministerio de Justicia.

\section{2.a) II. La regulación de la composición del Consejo General del Poder Judicial en la Ley Orgánica 1/1980 del CGPJ}

La perentoriedad existente con motivo de la precisa designación por el Consejo General del Poder Judicial de 2 miembros que configurarían el Tribunal Constitucional, originaría una aceleración de la regulación normativa del órgano de Gobierno del poder judicial, que en poco le favoreció, ya que en su permanente pretensión reivindicativa orientada a la reestructuración de la Administración de Justicia, el Consejo General va generando enfrentamientos con los distintos Gobiernos ${ }^{24}$, que acusan al órgano del ejercicio de competencias que no le corresponden. El artículo 7 de la Ley Orgánica del CPGJ determinaba que "De los veinte vocales ... Doce serán elegidos entre jueces y magistrados de todas las categorías judiciales, en los términos que establezca la presente Ley; cuatro a propuesta del Congreso y cuatro a propuesta del Senado, elegidos ambos por mayoría de $3 / 5$ de sus miembros".

El artículo 8, por su parte, matiza que los 12 vocales de procedencia judicial, serán elegidos "entre" jueces y magistrados ... y el artículo 12 de la Ley, por su parte, establece que estos vocales de procedencia judicial serán elegidos "por" todos los jueces y magistrados que estén en servicio activo.

De la redacción de ambos preceptos cabe mencionar lo siguiente:

1. A pesar de presentar un sistema mixto de elección, de procedencia judicial (12 miembros) y parlamentaria ( 8 miembros), sin em-

23 Mosquera, L.: "La posición del poder judicial en la Constitución Española de 1978", en La Constitución Española de 1978, estudio sistemático, ob. cit., pág. 730.

24 Fernández-Miranda Campoamor, C.: «El Consejo General del Poder Judicial...", ob. cit., pág. 85. 
bargo reflejan una afinidad de aspectos que concurren en todos los vocales $^{25}$ - de una u otra procedencia- y que podemos cifrar en los siguientes aspectos:

- pertenecen a la esfera de los juristas y abogados;

- obra sobre ellos una inamovilidad temporal, al estar sujetos al cargo durante 5 años.

2. No hubo discrepancias en torno al principio electivo de los vocales judiciales, cuya adopción fue pacífica y unánime por parte de los distintos grupos políticos ${ }^{26}$; lo cual pone de manifiesto que la idea latente es que el espíritu de la norma constitucional reflejara la designación del sector judicial "por" y "entre» los jueces.

3. La redacción de la Ley refleja la prevalencia del criterio jerárquico frente al representativo, lo que se desprende: 1) del número de magistrados frente al de jueces: 3 magistrados del Tribunal Supremo; 6 magistrados y 3 jueces; y 2) de la propia redacción del artículo 122.1 de nuestra Constitución al introducir el término jueces y magistrados "de carrera"; circunstancia ésta, por otra parte, que aunque aparentemente parece contrastar con la pretensión desjerarquizadora ${ }^{27}$ del art. 122.1, bajo la fórmula: "formarán un cuerpo único", sin embargo no hace sino reflejar una realidad constitucional: la existencia de categorías judiciales.

4. El elevado número de miembros que conforman el Consejo General le confiere un carácter de órgano deliberante o consultivo.

2.a) III. La regulación de la composición del Consejo General del Poder Judicial en la Ley Orgánica del Poder Judicial 6/1985 de 1 de julio

2.a) III.I. Causas inmediatas de la reforma de la regulación orgánica

La pretensión, legítima, de desapoderar al ejecutivo de su tradicional práctica de determinar la política judicial, con que se proyectó la cit., pág. 25.

25 Como ha señalado Xıl Ríos, J.A.: El Poder Judicial y su Consejo ..., ob.

26 Como ha señalado Gerpe Landin, M.: "La composición del Consejo General del Poder Judicial», en Revista de Estudios Constitucionales, pág. 150.

27 Mosouera, L.: "La posición del poder judicial ...", ob. cit., pág. 23. 
anterior Ley Orgánica de 1980 -que seguía fielmente el modelo italiano de autogobierno del Consejo, que facultaba a los Jueces y Magistrados la elección de sus representantes en el Consejo-, condujo a un frecuente enfrentamiento del órgano de Gobierno del poder judicial con el poder ejecutivo que se exteriorizó. El Consejo de Ministros, por acuerdo de 24 de septiembre de 1982, acusó de injerencia competencial al órgano del poder judicial, como paso previo a un conflicto entre órganos constitucionales del Estado.

También desde sede parlamentaria se suscitó acre crítica ${ }^{28}$ al Gobierno del poder judicial con motivo de la presentación de la Memoria del Consejo General de 1983, en la que las Cortes Generales reprocharían a la institución que aludimos, su dejación de las funciones que le competen.

\section{2.a) III.2. La enmienda Bandrés}

El clima de tensión suscitado entre distintos órganos constitucionales y la provisionalidad con la que fue regulado el primer Consejo General del Poder Judicial, provocó que en 1984 el ejecutivo socialista presentara un Proyecto de Ley Orgánica cuya finalidad era básicamente pacificar el encrespamiento a nivel institucional que había generado la desmesurada pretensión de "autogobierno" del órgano de gobierno del poder judicial, reduciendo el ámbito competencial del órgano de gobierno del poder judicial, pero sin modificar el sistema de designación de los miembros del Consejo, que se mantendría conforme a su elección "por y entre" los Jueces y Magistrados en activo.

En su paso por la Comisión de Justicia del Congreso, el Proyecto de Ley Orgánica del Poder Judicial fue apoyada por el Grupo Parlamentario Socialista y Grupo Nacionalista Vasco, la enmienda $n .^{\circ} 25$ de sustitución parcial del texto presentada por el Diputado de Euskadiko Ezquerra, D. Joan María Bandrés Molet, quien, invocando el principio de justicia popular recogido en el art. 117.1 de la Constitución, planteó el siguiente texto alternativo: "Los vocales serán nombrados 10 a propuesta del Congreso y 10 a propuesta del Senado, por mayoría de 2/3 de sus miembros, entre Jueces y Magistrados de todas las categorías judiciales y entre abogados y otros juristas ${ }^{29}$.

28 Gerpe Landin, M.: "La composición del Consejo ...», ob. cit., pág. 154.

29. Enmienda aprobada en Sesión de 6 de marzo de 1985 en la Comisión de Justicia. 
La intención de esta enmienda cabe interpretarla en el sentido siguiente:

1) La intervención del Parlamento para proceder a la elección de los miembros del Consejo de Gobierno del Poder Judicial, legitima a quienes, sin haber sido directamente elegidos por el pueblo, sin embargo están llamado a ejercer una potestad de la que éste es titular (art. 117.1 CE): "La justicia emana del pueblo».

2) La Constitución no predetermina necesariamente el sistema de designación de los 12 vocales judiciales, pudiendo ser elegidos, en consecuencia ya sea por los jueces, como por las Cámaras.

3) El sistema optado por la Ley Orgánica del Poder Judicial ofrece una oportunidad de democratizar el órgano frente a posibles intereses corporativistas.

Frente a esta argumentación, cabe mencionar una posición doctrinal contraria a la actual regulación de la Ley Orgánica del Poder Judicial, a la que nos adherimos y cuyos fundamentos referimos a continuación:

1) Por ser atentatoria contra la separación de poderes, posibilitando que en determinados supuestos de parlamentarismo mayoritario, el ejecutivo pueda presionar al Consejo.

2) Por contravenir el espíritu de la Constitución, cuya regulación referente a la intervención de las Cámaras, en el número máximo de vocales, se cfra en 8 -como señala Gerpe Landín ${ }^{30}$ - lo que es reforzado por los Reglamentos de las Cámaras que cifraban la propuesta de cada Cámara en 4.

3) Por haberse producido una mutación constitucional, que defrauda el espíritu de la Constitución -como señala Jiménez de Parga $^{31}$ - al instaurar un procedimiento de designación de los vocales distinto al empleado en la regulación orgánica anterior (1980) que lo hizo recaer en los Jueces y Magistrados (para la designación de 12 de los 20 vocales); se ha cambiado de criterio en las dos regulaciones orgánica y cabe plantearse lo siguiente: si la Constitución formaliza un régimen político que reconoce al poder judicial como un auténtico poder como el ejecutivo o el legislativo, no parece razonable que el poder judicial siga siendo un poder del Estado equiparable a los

156.

30 Gerpe Landín, M.: «La composición del Consejo General ....», ob. cit., pág.

31 Jiménez de PARGa, M.: La ilusión política. ¿Hay que reinventar la democracia en España?, Alianza Editorial, Madrid, 1993, pág. 141. 
otros, si los 20 vocales del órgano de gobierno del mismo son elegidos por el legislativo.

4) Por último, podemos esgrimir contra la parlamentarización de la designación de los vocales -invocando que la justicia emana del pueblo (art. 117), y que en consecuencia este sistema viene exigido por la Constitución- que es un descubrimiento sospechosamente tardio -como ha señalado De la Oliva- ya que no se impuso en la primera regulación orgánica, $y$, en todo caso, los jueces y magistrados tampoco son legitimados por unas elecciones, para impartir justicia, sino por su sometimiento a la Ley y al Derecho; y sin embargo, nadie cuestiona su legitimidad.

\section{Conclusión:}

Sin tomar posición sobre cuál pueda ser la mejor solución para resolver el problema suscitado con la designación de los miembros del Consejo de Gobierno del Poder Judicial, pero en todo caso, tratando de no regular las leyes vigentes, conforme a los intereses de quien se encuentre en el poder, sino buscando la mejoría en si de la norma, se haría conveniente modificar el sistema de cuotas exitentes, el cual, se ha constatado, que no ha producido el resultado deseado ${ }^{32}$; la tentación para los partidos de poder conrolar el órgano de gobierno dle poder judicial es muy grande, como para pretender que los partidos políticos actúen con imparcialidad.

En este sentido nos parece razonable la propuesta del Partido Popular, que vislumbra como vía de solución para la designación de vocales, según la cual, el Parlamento votaría no a los candidatos de los partidos políticos -que es lo que viene ocurriendo hasta ahora- sino a los candidatos que propongan las asociaciones profesionales: de esta manera serían los jueces y magistrados quienes designarían a sus representantes en el Consejo General; limitándose el Parlamento a avalar con su voto la decisión de aquéllos. Con lo cual se conjugan los dos ámbitos:

- No se desestima el origen popular de la justicia preceptuado en el art. 117, al hacer intervenir al Parlamento; $y$

- no se vacía de contenido corporativo al órgano de gobierno del poder judicial en la designación de sus miembros.

- $y$, por último, frente a un temor o peligro de incorporación de intereses corporativistas de la Magistratura, como ha señalado López

32 Jiménez de PaRga, M.: La ilusión política....., ob. cit., pág. 144. 
Guerra ${ }^{33}$, tampoco quedaría exenta la designación de los vocales por vía parlamentaria de posibles peligros de intereses de partido.

\section{2.a) III.3. La posición del Tribunal Constitucional}

Del examen sobre el recurso de inconstitucionalidad $n .^{\circ} 839 / 1985$ promovido por D. José M. ${ }^{a}$ Ruiz Gallardón contra la Ley Orgánica 6/1985 de 1 de julio, en relación con los preceptos concretos del art. 112 apartado 1 y 3 de la mencionada Ley Orgánica del Poder Judicial relativos a la designación de los miembros del Consejo General del Poder Judicial, hay que señalar lo siguiente:

Entienden los recurrentes que la asignación a las Cámaras de la facultad de proponer la totalidad de los 20 vocales vulnera el artículo 122.3 en relación con el 66.2 de la CE.

Por el primero se dispone que de los 20 miembros del Consejo "doce lo serán entre jueces y magistrados de todas las categorías judiciales en los términos que establezca la Ley Orgánica, 4 a propuesta del Congreso y 4 a propuesta del Senado elegidos en ambos casos por mayoría de $3 / 5$ de sus miembros entre abogados y juristas..."

Por el segundo precepto $(66.2 \mathrm{CE})$ se dispone que "Las Cortes Generales ejercen la potestad legislativa del Estado, aprueban los Presupuestos, controlan al Gobierno y tienen las demás competencias que les atribuye la Constitución".

Para los recurrentes, activando el art. 122 en conexión con el 66.2, aunque la CE no establece expresamente que los 12 vocales de procedencia judicial deben ser elegidos "por" y uentre" los jueces $y$ magistrados, tal imperativo se desprende de la interpretación sistemática, histórica y teleológica del precepto; y además, conforme al art. 66.2 CE de entre "las competencias que son atribuidas a las Cortes $\mathrm{Ge}$ nerales por la Constitución" no se incluye la facultad de proponer más que 8 vocales.

Los recurrentes invocan para desarrollar su tesis la independencia del poder judicial, que la cifran en 2 conceptos:

- La idea de autogobierno judicial.

- La representatividad interna.

33 López Guerra, L.: Ponencia sobre el Libro Blanco de la Justicia, presentada en los IX Cursos de Verano de la UNED, 13 de julio de 1998, Avila. 
El Tribunal Constitucional se ha ocupado de desmontar la pretensión del sector recurrente conforme a los siguientes argumentos:

1) La finalidad del Consejo del Poder Judicial es privar al Gobierno de determinadas funciones que pudieran interferir en la independencia de jueces y magistrados en el ejercicio profesional, atribuyéndolos a un órgano autonomo y separado del Gobierno, que garantiza la no injerencia del ejecutivo, pero no conduce necesariamente-según el Tribunal Constitucional ${ }^{34}$ - a reconocerse con ello la existencia de un autogobierno de los jueces, en la regulación constitucional del Consejo; ya que la independencia judicial no consiste en que el Consejo sea el órgano de autogobierno de los jueces, sino en que ocupe una posición de autonomía, no estando sometido a los demás poderes públicos.

2) Tampoco es admisible el carácter representativo invocado por los recurrentes ${ }^{35}$, al no configurar éste un órgano de una supuesta autoorganización de los jueces ni representar al Poder Judicial.

3) La independencia del órgano de gobierno del Poder Judicial tampoco peligra -según el Tribunal Constitucional ${ }^{36}$ - porque la designación de los vocales por la Cámara, no les convierte a éstos en delegados o comisionados del Congreso y del Senado, y en todo caso:

- No están vinculados al órgano proponente por la expresa prohibición del mandato imperativo (LOPJ art. 119.2).

- Están incursos en un plazo de mandato determinado: 5 años, que no coincide con el de las Cámaras (art. 119.2, LOPJ).

4) En cuanto a la posible vulneración por la LOPJ del artículo 66.2 de la CE que confiere al Parlamento funciones determinadas «... Y las demás competencias que les atribuye la Constitución" -y dado que la Constitución sólo reconoce al Parlamento la elección de 8 vocalespodría sostenerse una extralimitación competencial de las Cortes. EI Tribunal Constitucional empero reconduce la interpretación en el sentido de la no vulneración del mencionado precepto, considerando que "la recta interpretación del último inciso del art. 66.2 de la CE no es que las Cortes sólo puedan tener funciones expresamente contenidas en la Constitución, sino que éste les asigna algunas que forzosamente han de cumplir, y que la Ley no puede atribuir a ningún otro órgano; pero

34 S.T.C. n. ${ }^{\circ}$ 108/198686 de 29 de julio, BOE n. 193 de 13 de agosto de 1986. Fundamento jurídico 7 y 8.

${ }^{35}$ S.T.C. Aspecto sobre el que el Tribunal Constitucional ya tuvo ocasión de pronunciarse con anterioridad: S.T.C. n. ${ }^{\circ} 47 / 1986$ de 17 de abril.

${ }_{36}$ S.T.C. 108/1986, de 29 de julio. Fundamento jurídico $n .^{\circ} 10$. 
sin que ello suponga que, por Ley, no pueda reconocérseles otras que no estén específicamente mencionadas en la Constitución».

La conclusión a la que llega el Tribunal Constitucional es que la regulación orgánica del Poder Judicial ha creado un precepto que hace posible -aunque no necesaria- una actuación contraria al espíritu dela Constitución ${ }^{37}$, lo cual haría aconsejable su sustitución; pero de ello no se deduce su invalidez, "ya que su texto no impide una interpretación adecuada a la Constitución y no impone necesariamente actuaciones contrarias a ella».

Mi posición personal al respecto es la siguiente:

En primer lugar, la posición que asume un sector doctrinal ${ }^{38}$ claramente contrario a la designación por vía parlamentaria de la totalidad de los vocales del Consejo del Poder Judicial; en segundo lugar, la propia posición del Tribunal Constitucional que sin declarar inconstitucional el artículo 112.3 LOPJ vislumbra, sin embargo, su posible o aconsejable sustitución ${ }^{39} ;$ y, por último, la opinión vertida al respecto por parte de un sector de la magistratura ${ }^{40}$, quien, con la designación de la totalidad de los vocales por vía parlamentaria, considera que la institución del Consejo del Poder Judicial ha pasado a ser "un botín de los partidos políticos", con la carga política que ello comporta. Estos tres argumentos cuyo desarrollo tuvimos ocasión de analizar, me conducen a concluir que de poco habrá servido la cautela del Constituyente de crear un órgano de garantía de independencia de la función jurisdiccional de los jueces y magistrados respecto del ejecutivo, si por otro lado se permite la interferencia política que se deriva del sistema de elección parlamentaria de los 20 vocales, dejando cautiva la institución del poder de los partidos políticos y sus mayorías conyunturales en las Cámaras, lo que conduce al resultado final de la conveniencia y urgencia de la modificación de la LOPJ en materia de sistema de designación de los vocales del Consejo, para que en los umbrales del tercer milenio pueda, en rigor, formularse auténtica independencia del poder judicial.

37 S.T.C. $n .^{\circ}$ 108/1986. Fundamento jurídico n. ${ }^{\circ}$ 13: por el riesgo de que la lucha de partidos en el ámbito parlamentario origine en la elección de vocales un resultado que pueda empañar la independencia de la institución.

38 Jiménez de Parga, M.; Gerpe Landin, M.; Pérez de Ugena, A., mencionados en el apartado 2.a)(II.2.

39 S.T.C. $n .^{\circ} 108 / 1986$. Fundamento jurídico $n .{ }^{\circ} 13$ in fine.

40 Requero lBáNez, J.L. (Magistrado y Secretario General de la Asociación Profesional de la Magistratura): "La transición inconclusa de la justicia", en el diario El Mundo, 11-6-1998. 


\section{2.b) Funciones de gobierno del Consejo General del Poder Judicial}

Aunque con carácter general la función atribuida al Consejo General es la de carácter organizativo y administrativo -evitando así interferencias del ejecutivo-, para que sean los juzgados y tribunales quienes desempeñen la función jurisdiccional, la concreción de lo que pueda constituir la esfera funcional del Consejo de Gobierno del poder judicial, no está definido en la Constitución; el art. 122.2 de la CE, hace remisión a la Ley Orgánica de desarrollo del precepto para determinar cuáles serán tales funciones, lo que ha abonado el terreno de la polémica en torno a las dos concepciones que pivotan en relación con las cotas de autonomía de gobierno del Consejo: una limitada y otra absoluta.

Desde una concepción puramente instrumental como ha reconocido Xiol Ríos ${ }^{41}$, hay que mencionar la asignación de funciones tendentes exclusivamente a justificar la independencia y eficacia de la función jurisdiccional, y por tanto debe entenderse como autonomía de gobierno «limitada». Desde esta consideración, conviene rescatar para el exclusivo gobierno por parte del Consejo General del Poder Judicial, determinados ámbitos sobre los que ancestralmente el ejecutivo había proyectado su intervención, y en la actualidad, sin embargo, por constituir garantía de independencia del poder judicial frente al ejecutivo, configuran el núcleo respecto al que sustancialmente debe proyectarse la autonomía de gobierno del poder judicial. Se trataría de todo lo concerniente en materia de: designación de cargos judiciales, nombramientos, ascensos en la carrera, y potestad disciplinaria.

Desde esta consideración, cabe afirmar que el núcleo competencial diseñado por la Ley Orgánica se centra básicamente en torno al estatuto y régimen disciplinario de jueces y magistrados -que en definitiva configura la esfera más delicada en materia de garantizar ${ }^{42}$ la independencia judicial-, pero la regulación orgánica no se limitó en exclusiva a este ámbito, sino que extendió sus facultades a materias relativas al estatuto de los Secretarios de los Juzgados y Tribunales, y al sistema de selección del personal judicial.

41 XıL Rios, J.A.: Composición y función del Consejo General del Poder Judicial, pág. 41. Concepción instrumental frente a tesis absolutistas tendentes a atribuir al Consejo General también otras funciones de gestión de medios materiales para el ejercicio de la potestad jurisdiccional.

${ }_{42}$ MuÑOz MACHADO, S.: "La independencia judicial y el problema de la relación de la justicia con los demás poderes del Estado", en Actualidad y Perspectivas del Derecho Público a fines del siglo XX, pág. 271; "para privar al gobierno de funciones que pueden permitirle interferirse en la actividad de los jueces, asignándolos a un órgano autónomo e independiente". 
2.b) I Las funciones del Consejo General del Poder Judicial reguladas en la Ley Orgánica del Consejo General del Poder Judicial $1 / 1980$ de 10 de enero

Tal como fue redactada la regulación orgánica de 1980 pueden diferenciarse los siguientes ámbitos competenciales según su contenido (artículos 2,3 y 5):

2.b) I.1. De propuesta:

2.b) I.1.1. Para el nombramiento del Presidente del Tribunal Supremo.

2.b) I.1.2. Para el nombramiento de 2 magistrados del Tribunal Constitucional.

2.b) I.2. De selección, provisión de destinos, ascensos y régimen disciplinario.

2.b) I.2.1. De Jueces y Magistrados.

2.b) I.2.2. De Secretarios judiciales.

2.b) I.3. De selección, formación y perfeccionamiento.

2.b) I.4. Nombramiento del Director de la Escuela Judicial.

2.b) 1.5. Nombramiento de Jueces, Magistrados y Presidentes.

2.b) I.6. Dentro de la administración interna:

2.b) I.6.1.Nombramiento del Secretario General.

2.b) I.6.2. Nombramiento de gabinetes y servicios del Consejo General del Poder Judicial.

2.b) I.6.3.Elaboración y presupuesto del Consejo General del Poder Judicial.

2.b) 1.7. Potestad normativa, de iniciativa o propuesta.

2.b) I.8. Potestad reglamentaria sobre su organización y funcionamiento.

2.b) II. Las funciones del Consejo General del Poder Judicial en la Ley Orgánica del Poder Judicial 6/1985 de 1 de julio y tras las reformas introducidas por la Ley Orgánica 16/1994

El ámbito competencial conferido por esta Ley Orgánica al órgano de gobierno del Poder Judicial produjo una seria regresión respecto a la 
legislación anterior, como ha señalado De Esteban ${ }^{43}$, y que se cifra: en primer lugar en la pérdida del carácter decisorio de sus competencias, tal como contemplaba la Ley Orgánica del Consejo General del Poder Judicial y no así la Ley Orgánica del Poder Judicial, sin perjuicio de que lo sean por configurar facultades expresamente asignadas en la Constitución.

En segundo lugar, por haber sido sustraida del Consejo General las siguientes facultades:

- De selección, formación y perfeccionamiento, aprobación de programa y nombramiento de tribunales, del personal auxiliar de la Administración de Justicia.

- De selección, provisión de destinos, ascensos y régimen disciplinario de los secretarios de juzgados y tribunales.

- Del nombramiento del Director de la Escuela Judicial.

Pasamos a contemplar a continuación cómo han quedado reflejadas en la nueva regulación orgánica del Poder Judicial las atribuciones asignadas a este órgano.

2.b) II.1. De propuesta

- Para el nombramiento del Presidente del Tribunal Supremo que lo es a su vez del propio Consejo, (art. 107.1, LOPJ) debiendo formularse la propuesta por mayoría de $3 / 5$, como específicamente define la ley frente al régimen de mayoría absoluta que definia la Ley Orgánica 1980 (art. 27) para la 1. ${ }^{\text {a }}$ vuelta y, de no lograrse, mayoría simple en la 2. ${ }^{a}$.

Este nombramiento debe verificarse por Orden y presentación a Real Decreto, refrendado por el Ministro de Justicia, lo que enfatiza ${ }^{44}$ la posición del Gobierno como el responsable de la justicia, sin perjuicio del deslinde competencial del Consejo.

- Para el nombramiento de 2 miembros del Tribunal Constitucional por idéntica mayoría cualificada de $3 / 5$, debiendo velar el Tribunal por el cumplimiento de los requisitos exigidos en su art. $10 \mathrm{~F}$ (art. 107.2, LOPJ).

- De nombramiento de Secretario General y miembros de los gabinetes dependientes del mismo, que también contemplaba la Ley Orgánica de 1980 (art. 107.6, LOPJ). sa), de 2-X-1991.

43 De Esteban, J.: "Las tribulaciones del poder judicial», en El Mundo (pren-

${ }_{44}$ Como ha señalado Fernández-Miranda Campoamor, C.: «El Consejo General del Poder Judicial...", ob. cit., pág. 54. 
- De consulta ${ }^{45}$ al Consejo - de carácter no vinculante- para efectuar el nombramiento del Fiscal General del Estado (art. 108-4, LOPJ).

2.b) II. 2. De inspección de Juzgados y Tribunales (art. 107-3, LOPJ 1980 y art. 117 del Reglamento ${ }^{46}$ de Organización y Funcionamiento del Consejo General).

El servicio de inspección es el órgano técnico que ejerce la comprobación y control del funcionamiento de los servicios de la Administración de Justicia, a instancia del Pleno del Consejo o de su Presidente.

El servicio de inspección está presidido por el Jefe del Servicio de inspección que debe pertenecer a la carrera judicial y tener la categoría de Magistrado del Tribunal Supremo. A través de la sección de informes, este servicio elabora los informes referentes a la actuación profesional de Jueces y Magistrados.

2.b) Il. 3. Selección, formación y perfeccionamiento, provisión de destinos y ascensos (art. 107-4 y 7; y Reglamento del Consejo, art. 108).

Es ésta la atribución más emblemática de las que son asignadas al Consejo General, y la que verifica más sustantivamente la independencia del ejecutivo, al preservar de la posible inferencia de éste todo aspecto concerniente a la carrera judicial, como garantía para los jueces y magistrados en el ejercicio de su profesión; ya que precisamente era ésta una de las esferas en las que intervenía con anterioridad el Gobierno y del que se le ha rescatado, merced a la atribución de tales facultades al órgano de gobierno de la Judicatura.

A pesar de ello, se desprende una notable diferencia entre el ámbito competencial asignado al Consejo en 1980 y el conferido por la Ley Orgánica de 1985, al compartir esta última con el Ministerio de Justicia determinadas competencias que afectan al sistema de selección de jueces y magistrados; lo que se traduce en una relevancia del papel que juega el ejecutivo con esta regulación. Este protagonismo del ejecutivo se hace patente, asimismo, a través de la incorporación del $4 .^{\circ}$ turno con que, el Gobierno se asegura su intervención e influencia ${ }^{47}$, al con-

45 Estas facultades de orden consultivo, frente a otras competencias decisorias que pone de manifiesto la ley, adquieren, en todo caso una excepcional importancia como ha mencionado Xiol Ríos, al tratarse de un órgano investido de una especial «auctoritas". XIOL Ríos, ob. cit., pág. 53.

46 Reglamento de Organización y Funcionamiento del Consejo General del Poder Judicial. Acuerdo de 22 de abril de 1986.

47 Fernández-MiRanda Campoamor, C.: «El Consejo General del Poder Judicial ...", ob. cit., pág. 57. 
figurarse los plazos del concurso de dicho turno conforme a las bases definidas por el Ministerio de Justicia.

\section{2.b) II. 4. Competencia presupuestaria}

Tanto la regulación de la Ley Orgánica de 1980, como la de 1985, confieren al Consejo General una atribución puramente residual en materia de intervención para elaborar a través de la Comisión Presupuestaria lo que no pasa de ser un simple anteproyecto del Presupuesto del Consejo (art. 37.1, LOPJ y artículos 83 y 87 del Reglamento del Consejo General del Poder Judicial) y que en todo caso no es vinculante para el gobierno.

No deja de contrastar -como diferencia evidente- la distinción de tratamiento, a efectos presupuestarios, entre el Consejo General, cuya intervención en esta materia no vincula al Gobierno, quien se reserva la decisión final, frente a lo que acontece con el Tribunal Constitucional (disposición adicional segunda, 1) a quien se le ordena elaborar su propio presupuesto, asignándole una sección específica dentro de los Presupuestos Generales del Estado. No ha faltado quien vea en este diferente tratamiento normativo ${ }^{48}$, el reconocimiento de la dispar relevancia constitucional que de uno y otro órgano constitucional, se refleja en la norma suprema.

\section{2.b) II. 5. Propuesta normativa}

No disfruta el Consejo de competencia en materia legislativa ni en la Ley Orgánica del Consejo General del Poder Judicial de 1980, a pesar de la confusión que introdujo la desafortunada redacción de su art. $3^{49}$, ni con posterioridad, con la regulación orgánica de 1985 del poder judicial y después de la modificación de la Ley Orgánica 16/1994 de 8 de noviembre, en cuyo precepto 108, se alude exclusivamente a una competencia por parte del Consejo General, de mera información de los anteproyectos de leyes y disposiciones generales del Estado, en relación con un elenco concreto y cerrado en el que cabe proyectarse

48 Fernandez-Miranda Campoamor, C.: «El Consejo General del Poder Judicial...n, ob. cit., pág. 57.

${ }_{49}$ "El Consejo ... dispondrá de facultades de iniciativa o propuesta, y en todo caso de informe en las siguientes materias..." 
esta delimitada y tasada competencia normativa, que asume un carácter imperativo para el Consejo: "El Consejo ... deberá informar ..." y con una temporalidad o plazo defínido: de treinta días, con carácter general, o de 15 en casos de urgencia.

No han faltado críticas ${ }^{50}$ en relación con la escasa intervención que la regulación orgánica autoriza al órgano de Gobierno en el plano competencial normativo, invocando que podría haber asumido un papel más relevante, al menos en aquellas materias que le conciernen dentro del ámbito de la justicia, en lo que pudiera ser una fase de preiniciativa legislativa, sin perjuicio de que el Gobierno pudiera o no aceptarla. Todo ello dentro del techo de la iniciativa legislativa que el artículo 87 de la Constitución confiere en exclusiva al Gobierno, Parlamento, Asambleas Legislativas y al cuerpo electoral, con diáfana exclusión del Consejo General.

Frente a esta posición no podemos sino señalar que aún en ese mínimo margen de acción que pudiera asumir hipotéticamente el Consejo General, en lo que se ha mencionado colaboración razonable del Consejo con el Gobierno en fase de pre-iniciativa legislativa, que además no sería vinculante para el Gobierno, si el Gobierno la adoptara, se llegaría al resultado de vulnerar el espíritu de la norma del art. 87 que expresamente confiere esa iniciativa a los órganos que menciona con diáfana intención y ninguno más.

\section{2.b) II. 6. Potestad reglamentaria}

Esta actividad del Consejo ha originado amplia polémica doctrinal ${ }^{51}$, en torno al alcance que ésta pueda adoptar. Dada la limitación definida por el artículo $97 \mathrm{CE}$ que atribuye la potestad reglamentaria al Gobierno, se plantea el problema de si el Consejo General del Poder Judicial asume tal competencia reglamentaria y en qué extensión, especialmente tras la excesiva amplitud y ambigüedad de la regulación del art. $5 .^{\circ}$ de la LOCGP de $1980^{52}$. El carácter genérico de la atribución

50 Fernández-Miranda Campoamor, C.: «El Consejo General del Poder Judicial ...", ob. cit., pág. 58.

51 Pérez Ugena, A.: En tesis doctoral (posterior publicación), El Consejo General del Poder Judicial y las Cortes Generales, pág. 216.

52 Art. 5 L.O.C.G.P. 1980: "... podrá dictar Reglamentos sobre su organización y funcionamiento, así como sobre el régimen del personal y servicios y demás materias de su competencia, dentro del ámbito de la presente Ley. Estos Reglamentos deberán ser aprobados por mayoría de 3/5 de sus miembros". 
residual que contempla este artículo, podría hacer pensar, como señala Porras Nadales ${ }^{53}$, no sólo la existencia de un espacio natural para el desarrollo del reglamento organizativo interno o "ad intra", sino una posible potestad reglamentaria que, desbordando su ámbito interno, llegara a afectar la autonomía del poder judicial y a la independencia de jueces y magistrados.

La posterior regulación orgánica de 1985 despejó en buena medida la confusión generada por la anterior Ley Orgánica al aclarar en el art. 110 dos aspectos concretos:

1. La atribución de la potestad reglamentaria autoorganizativa al Consejo.

2. La atribución genérica de la potestad reglamentaria residual de la propia Ley al Gobierno, conforme a una disposición adicional primera de la Ley Orgánica ${ }^{54}$.

Sin embargo, esta Disposición introdujo un hipotético conflicto de atribuciones que hizo precisa la intervención del Tribunal Constitucional ${ }^{55}$. La polémica se cifraba en determinar si la atribución asignada al Gobienro para el desarrollo de la LOPJ (Disposición Adicional Primera, 2: «El Gobierno aprobará los Reglamentos que exige el desarrollo de la presente Ley Orgánica»), rebasaba los límites que asigna el art. 97 de la CE a la potestad reglamentaria del Gobierno, la cual correspondería al Consejo en virtud de los poderes implícitos de las funciones que le atribuye la Constitución.

El Tribunal Constitucional dirime en su fundamentación jurídica la controversia conforme a dos fases:

En primer lugar rechaza el Tribunal Constitucional un intervencionismo en el desarrollo reglamentario de la Ley Orgánica, tanto para el Consejo General, como para el Gobierno, en materia del ejercicio de la potestad jurisdiccional de jueces y magistrados, así como en su propio estatus, que viene determinado exclusivamente por la Ley Orgánica (art. 122.1 CE).

En segundo lugar, admite una franja de regulación infralegal que puede afectar a ese estatus de los jueces y magistrados, respecto a la

53 Como ha manifestado Porras Nadales, A.: "El Consejo General del Poder Judicial", en Revista Española de Derecho Constitucional, n. ${ }^{\circ} 19$, enero-abril, 1987 , pág. 236.

54 Recurrida ante el Tribunal Constitucional por conflicto de atribuciones por Alianza Popular.

55 Recurso de Inconstitucionalidad $n .^{\circ} 839 / 1985$, promovido por D. José M.A Ruiz Gallardón, S.T.C. 108/86 de 29 de julio. 
que exigencias prácticas pueden imponer una regulación de carácter auxiliar por vía reglamentaria.

En tercer lugar, esta posible regulación accesoria, en ningún caso puede afectar al conjunto de derechos $y$ deberes que configuran el estatuto de jueces y magistrados.

En cuarto lugar, siempre dentro de los límites señalado, la posible regulación reglamentaria residual que analizamos -sobre la que no recaiga reserva de Ley Orgánica- podrá verificarse aunque desborde su potestad reglamentaria "ad intra" invadiendo un ámbito competencial «ad extra» (que desborda el ámbito de su organización y funcionamiento interno), tanto por el Consejo General (en el mismo ámbito competencial que le confiere el art. 110 de la LOPJ), como de igual modo por el Gobierno, sin poderse precisar a priori, en qué casos puede corresponder a una u otra instancia, como ha señalado el Tribunal Constitucional.

La modificación del artículo 110 LOPJ por la Ley Orgánica 16/1994 de 8 de noviembre se ocupa de definir pormenorizadamente $y$ casi exhaustiva cuales son los supuestos diversos sobre los que puede proyectar su potestad reglamentaria, lo que de alguna manera minimiza -si no hace desaparecer en la actualidad- la sutil frontera de parcela común existente entre el Gobierno y el Consejo de regulación infralegal, sobre cuya competencia respectiva el Tribunal Constitucional consideró que no se podía precisar a priori.

\section{EL ESTATUTO JURÍDICO DE LOS MIEMBROS DEL CONSEJO GENERAL DEL PODER JUDICIAL}

La exigencia del desarrollo constitucional preceptuado en el art. 122 de la $C E$, según el cual se establece que "la Ley Orgánica del Poder Judicial determinará ... el estatuto de los Jueces y Magistrados de carrera ..." condujo a que la Ley Orgánica del Poder Judicial se ocupara de regular en los artículos 117 a 122 la posición jurídica de los vocales del Consejo.

Una de las manifestaciones en que se plasma la independencia judicial -como se ha mencionado en la Exposición de Motivos de la LOPJ-, se hace patente uen la absoluta sustracción del estatuto jurídico de Jueces y Magistrados a cualquier posible interferencia que parta de los otros poderes del Estado". La doctrina ha reconocido que el Estatuto de Jueces y Magistrados constituye uno de los aspectos más sensibles desde el punto de vista de garantía de independencia del poder judicial, como 
ha señalado Xiol Ríos ${ }^{56}$ y por tanto de los aspectos más justificados para ser confiado a un órgano de gobierno autónomo. Desde esta consideración, la finalidad del Consejo es -como ha señalado el Tribunal Constitucional ${ }^{57}$ - privar al Gobierno de esas funciones y transferirlas a un órgano autónomo, propio de un estado de derecho a este efecto.

En definitiva, como ha afirmado el Tribunal Constitucional, «la defensa de la independencia judicial no consiste en que el Consejo sea el órgano de autogobierno de los jueces, sino en que ocupe una posición autónoma y no subordinada a los demás poderes públicos".

En este sentido, la presente Ley Orgánica del Poder Judicial reconoce al Consejo General todas las atribuciones necesarias para la aplicación del Estatuto jurídico de los Jueces y Magistrados, en materia de nombramientos, ascensos, inspección y régimen disciplinario.

Muy esquemáticamente, siguiendo la regulación orgánica, podemos agrupar los diferentes dispositivos con que formula la Ley la autonomía de los Jueces y Magistrados, conforme al siguiente elenco:

1. Un reconocimiento de la capacidad jurídica de los miembros del Consejo, que los diferencia en dos grupos distintos, sin perjuicio de su tratamiento igualitario:

- Jueces y Magistrados.

- Abogados y otros juristas.

Introduce la regulación constitucional este sistema mixto configurado por 12 vocales pertenecientes a la carrera judicial (art. 122.3 CE), representando éstos -aunque no se define en qué proporción- las distintas categorías judiciales: Magistrados del Tribunal Supremo; Magistrados y Jueces; y por 8 vocales sobre quienes recae una triple condición:

- de abogados y juristas;

- de reconocida experiencia;

- con más de 15 años de ejercicio.

Este precepto parece haber abrigado la intencionalidad de excluir del concepto genérico de "juristas" a jueces y magistrados -ya incluidos expresamente entre los 12 vocales de procedencia judicial-con el fin de no potenciar el riesgo corporativista ${ }^{58}$.

56 Xıol Rios: Composición del Consejo General del Poder Judicial, ob. cit., pág. 51.

S.T.C. n. ${ }^{\circ} 108 / 1986$ de 29 de julio. Fundamento jurídico $n .^{\circ} 7$.

58 Gerpe Landín, M.: La composición del Consejo General del Poder Judicial, ob. cit., pág. 171. 
2. A través de un pormenorizado y rígido régimen de incompatibilidades (art. 117.1 L.O.) que comporta la dedicación exclusiva de los miembros a su función de vocales del Consejo, al amparo de peligrosas presiones o influencias nada convenientes para quienes configuran un órgano autónomo e independiente. Expresa incompatibilidad pues del cargo con cualquier otro puesto o profesión, público o privado, remunerado o no; viéndose incrementada esta incompatibilidad con las específicas de los Jueces y Magistrados mencionadas en el art. 389.2 de la LOPJ; por su parte, el art. 15 del Reglamento de organización y funcionamiento del Consejo remite asimismo en materia de incompatibilidades de los miembros del Consejo a los artículos 117.1; 119.1; 120 y 121 de la Ley Orgánica 6/1985 de 1 de julio.

3. La situación administrativa que ampara a quienes sean funcionarios públicos -tanto judiciales como no judiciales- será la de servicios especiales. El artículo 16 del Reglamento ${ }^{59}$ del Consejo establece que en la primera reunión tras su constitución, el Pleno del Consejo declarará los Jueces y Magistrados incursos en la referida situación y comunicará al órgano competente el nombramiento y posesión de los miembros del Consejo que sean funcionarios de otros Cuerpos y carreras, a fin de que surta efecto el régimen de incompatibilidades.

4. El art. 118 LOPJ contempla la cobertura de reserva de plaza para quienes ocupen un cargo de duración determinada, de tal forma que al término del plazo en su cargo, tienen garantizada su reincorporación al destino del que salieron.

5. Una de las características más emblemáticas del estatuto jurídico de los miembros del Consejo es la no sujeción al órgano proponente (el Parlamento) por mandato imperativo alguno (art. 119.2, LOPJ); ni pueden recibir instrucciones de sus electores, ni pueden ser revocados por aquéllos; garantizando en consecuencia la inamovilidad de su cargo, salvo por agotamiento de su mandato, renuncia, incompatibilidad o incumplimiento.

6. La duración del mandato de 5 años (art. $122 \mathrm{CE}$ ) tiene la virtualidad de no coincidir con el de las Cámaras, lo que aporta una mayor desconexión del Parlamento y garantía de la independencia del Consejo, impidiendo que los vocales, siendo nombrados por aquél, actúen como delegados o comisionados del Parlamento. Esta asincronía temporal con las Cámaras -como ha señalado Gerpe Landín ${ }^{60}$ se acompa-

59 Reglamento de organización y funcionamiento del Consejo General del Poder Judicial. Acuerdo 22 de abril de 1986.

60 Gerpe Landín, M.: La composición del Consejo ..., ob. cit. 
sa de la circunstancia de no poder ser revocados los vocales por sus electores, así como no poder ser reelegidos de forma inmediata, con lo que se garantiza la independencia de criterio que podría verse condicionado por quienes deben renovar el mandato.

7. Prohibición de promoción profesional durante el ejercicio del cargo de vocal (art. 120 LOPJ). La pretendida asepsia política del órgano impide, de forma razonable, que los vocales sean promovidos durante su mandato, en el ámbito de carrera judicial, (salvo los que se deriven del ascenso en el escalafón) para impedir que tales méritos se utilicen en beneficio propio, sin perjuicio de que profesionalmente to merezcan.

8. Obligaciones y Derechos de los miembros del Consejo: Los artículos 17 y 18 del Reglamento del Consejo, cifran la relación estatutaria de deberes y derechos que presiden la actuación de los miembros del Consejo conforme a los siguientes:

- Obligaciones de los miembros del Consejo: formen parte.

a) Asistencia a las sesiones del Pleno y Comisiones de las que

b) Despachar las ponencias para las que fueron designados.

c) Guardar secreto de las deliberaciones.

d) Respetar las incompatibilidades que les afecten.

e) Ejercer fielmente las obligaciones de su cargo.

- Derechos de los miembros del Consejo:

a) Sufragio activo y pasivo, elegir y ser elegido.

b) Exponer su opinión en las reuniones a las que asista.

c) A que conste en Acta el sentido de su voto o la opinión expresada.

d) A solicitar que un asunto se deje sobre la Mesa del Consejo para un estudio más reflexivo del mismo.

e) Formulación de propuestas e inclusión en el Orden del día.

f) Acceso a la actividad del Consejo y Actas del mismo.

g) Tratamiento propio de los miembros de un órgano constitucional.

9. Exigencia de mayoría cualificada de los $3 / 5$ de cada Cámara tal como define el artículo 112 de la Ley Orgánica del Poder Judicial. 